\begin{tabular}{|l|l|l||}
\hline \multicolumn{2}{|c|}{ PublisherInfo } \\
\hline \hline PublisherName & $:$ & BioMed Central \\
\hline \hline PublisherLocation & $:$ & London \\
\hline \hline PublisherImprintName & $:$ & BioMed Central \\
\hline \hline
\end{tabular}

\title{
U/S-aided thoracentesis in the ICU
}

\begin{tabular}{||l|l|l||}
\hline \multicolumn{2}{|c||}{ ArticleInfo } \\
\hline \hline ArticleID & $:$ & 4154 \\
\hline \hline ArticleDOI & $:$ & $10.1186 /$ ccf-1999-2061 \\
\hline \hline ArticleCitationID & $:$ & 2061 \\
\hline \hline ArticleSequenceNumber & $:$ & 13 \\
\hline \hline ArticleCategory & $:$ & Paper Report \\
\hline \hline ArticleFirstPage & $:$ & 1 \\
\hline \hline ArticleLastPage & $:$ & 3 \\
\hline \hline & & RegistrationDate : 1999-10-14 \\
ArticleHistory & $:$ & OnlineDate $\quad$ 1999-10-14 \\
\hline \hline ArticleCopyright & $:$ & Current Science Ltd1999 \\
\hline \hline ArticleGrants & $:$ & \\
\hline \hline ArticleContext & $:$ & 1305422 \\
\hline \hline
\end{tabular}




\section{Keywords}

Intensive care, pleural effusion, thoracentesis, ultrasound

\section{Comments}

It is well known to the ICU community that the supine chest x-ray has poor sensitivity for the diagnosis of pleural effusion, although it is sometimes difficult to convince our radiological colleagues of this if they are expected to perform the ultrasound on the ICU! This study reinforces current practice that ultrasound is superior in diagnosis and enables safe aspiration of pleural effusions. However, it goes a stage further by showing that the intensivist can safely utilise ultrasound to diagnose and aspirate effusions. ICUs which rely on radiologists to perform ultrasound no longer need to be at their beck and call!

\section{Introduction}

Pleural effusions are notoriously difficult to diagnose with a supine chest x-ray in the ICU, and may easily be mistaken for consolidated or atelectatic lung. Aspiration of an effusion in these critically ill patients may offer benefits in terms of microbiological diagnosis and improvements in lung compliance, but carries the risk of pneumothorax which may severely compromise the ventilated patient. Ultrasound has better diagnostic sensitivity for pleural effusion in the supine patient, and may also offer a safety advantage over blind aspiration following diagnosis with a chest $\mathrm{x}$-ray.

\section{Aims}

To evaluate the safety of ultrasound guided aspiration of pleural effusions in critically ill patients.

\section{Methods}


Forty consecutive ventilated patients, with an ultrasound diagnosis of pleural effusion, underwent ultrasound guided aspiration of this effusion. Forty-five procedures were performed, of which seven were therapeutic and the remainder diagnostic. A description of the procedures is given in the paper. Of importance, is that aspiration was only performed if the inspiratory interpleural distance was $>15 \mathrm{~mm}$. Follow up chest x-rays were performed over the next 48 hours.

\section{Results}

No complications occurred and fluid was successfully aspirated in 44 of 45 procedures. Of 45 procedures, 40 aspirated fluid easily within 10 seconds at the first attempt. Supine chest x-rays only identified pleural effusions in 27 of the proven 44 cases.

\section{Discussion}

Ultrasound is eminently superior in identifying pleural effusions when compared to the supine x-ray in the ventilated patient, and aspiration can be performed safely provided an interpleural distance of 15 $\mathrm{mm}$ is adhered to. It is a simple and easy procedure and avoids the need for unnecessary irradiation.

\section{Additional information}

An editorial and another study conducted in a surgical ICU appear in the same edition of this journal (Intensive Care Med 1999, 25:1029). This second study involved a much larger patient group, although the majority of these patients were not ventilated. No information is given on the technique of ultrasound guided aspiration used (which was very precise in Lichtenstein's paper). This may reflect the complication rate of $2.4 \%$.

\section{References}

1. Lichtenstein D, Hulot J-S, Rabiller A, Tostivint I, Meziere G: Feasibility and safety of ultrasoundaided thoracentesis in mechanically ventilated patients. Intensive Care Med. 1999, 25: 955-958. 